\title{
The Lateral Amygdaloid Nucleus: Sensory Interface of the Amygdala in Fear Conditioning
}

\author{
Joseph E. LeDoux, ${ }^{1}$ Piera Cicchetti, ${ }^{2}$ Andrew Xagoraris,, ${ }^{2}$ and Lizabeth M. Romanski' \\ ${ }^{1}$ Center For Neural Science, New York University, New York, New York 10003, and 'Laboratory of Neurobiology, Cornell \\ University Medical College, New York, New York 10021
}

\begin{abstract}
Previous work has implicated projections from the acoustic thalamus to the amygdala in the classical conditioning of emotional responses to auditory stimuli. The purpose of the present studies was to determine whether the lateral amygdaloid nucleus (AL), which is a major subcortical target of projections from the acoustic thalamus, might be the sensory interface of the amygdala in emotional conditioning. Lesions were placed in AL of rats and the effects on emotional conditioning were examined. Lesions of $A L$, but not lesions of the striatum above or the cortex adjacent to the $A L$, interfered with emotional conditioning. Lesions that only partially destroyed AL or lesions placed too ventrally that completely missed AL had no effect. AL lesions did not affect the responses elicited following nonassociative (random) training. $A L$ is thus an essential link in the circuitry through which auditory stimuli are endowed with affective properties and may function as the sensory interface of the amygdala during emotional learning.
\end{abstract}

Most of the stimuli we encounter in daily life are neither intrinsically good nor bad and only acquire affective qualities through our experiences with them. For example, stimuli that occur at the same time as some unpleasant event can, by association, acquire aversive properties.

In laboratory studies, classical conditioning procedures are used to study the brain mechanisms underlying the formation of emotional associations. Typically, a relatively neutral stimulus, such as a tone or light, is paired with an aversive event, such as footshock. After only a few pairings, the previously neutral stimulus becomes aversive and can itself evoke an emotional reaction. The effects of conditioning develop rapidly and persist for long periods of time, reflecting the biological significance of the learning experience for the organism. For these reasons, emotional conditioning is an extremely valuable tool for studying learning mechanisms.

Considerable evidence now suggests that the amygdala, and particularly the central nucleus of the amygdala (ACE), is an essential link in the neural circuit underlying aversive emotional conditioning (fear conditioning): lesions or pharmacological ma-

Received June 9, 1989; revised Aug. 24, 1989; accepted Sept. 19, 1989.

Supported by MH38774 and a Grant in Aid from the New York Heart Association. J.E.L. is an Established Investigator of the American Heart Association. The studies described in this paper were performed in The Laboratory of Neurobiology at Cornell University Medical College.

Correspondence should be addressed to Dr. J. E. LeDoux, Center for Neural Science, Meyer Building, New York University, 6 Washington Place, New York, NY 10003.

Copyright $(\mathcal{C} 1990$ Society for Neuroscience $0270-6474 / 90 / 041062-08 \$ 02.00 / 0$ nipulations confined to or including ACE interfere with the acquisition and expression of autonomic and behavioral conditioned fear responses (Blanchard and Blanchard, 1972; Kapp et al., 1979; Gallagher et al., 1981; Gentile et al., 1986; Hitchcock and Davis, 1986; Iwata et al., 1986a); unit activity in ACE changes in reliable and predictable ways during aversive conditioning (Applegate et al., 1982; Pascoe and Kapp, 1985); electrical or chemical stimulation of ACE elicits autonomic and behavioral responses that resemble conditioned emotional responses (Reis and Oliphant, 1964; Kapp et al., 1982; Galeno and Brody, 1983; Iwata et al., 1987); and lesions of brain-stem areas to which ACE projects (Hopkins and Holstedge, 1978; Krettek and Price, 1978a; Price and Amaral, 1981; Schwaber et al., 1982; Van der Kooy et al., 1984) separately interfere with autonomic and behavioral responses elicited by conditioned emotional stimuli (Smith et al., 1980; Francis et al., 1981; Iwata et al., 1986b; LcDoux et al., 1988). The latter observation suggests that efferent targets of the ACE are involved in the organization of specific motor responses (autonomic or behavioral) and that ACE is the final site of response-independent integration in the emotional learning circuit. The essential neural plasticity underlying fear learning, therefore, is likely to take place in ACE and/or structures afferent to it.

An important issue thus concerns the afferent pathways through which the amygdala receives information about sensory stimuli. Although projections from modality-specific sensory processing areas of the neocortex to the amygdala exist (Whitlock and Nauta, 1956; Jones and Powell, 1970; Herzog and van Hoesen, 1975; Aggleton et al., 1980; Turner et al., 1980; Amaral, 1987), removal of cortical sensory areas does not interfere with the conditioning of fear responses to auditory stimuli (LeDoux et al., 1984). However, the amygdala also receives projections from acoustic processing areas in the posterior thalamus (Vecning, 1978; Ottersen and Ben-Ari, 1979; Turner and Herkenham, 1981; Russchen, 1982; LeDoux et al., 1984, 1985), and these projections mediate the establishment of conditioned fear responses to acoustic stimuli (Iwata et al., 1986a; LeDoux et al., 1986b).

It is possible that in auditory fear conditioning the sensory relay from the thalamus is to ACE. Anterograde tracing studies show that the capsular portions of ACE receive fibers from posterior thalamic areas (Turner and Herkenham, 1981; LeDoux et al., 1985, 1990). Moreover, retrograde tracing studies show that cells in the posterior thalamus project to ACE (Veening, 1978; Ottersen and Ben-Ari, 1979; LeDoux et al., 1985). In these latter studies, the cells of origin of the thalamic projection to ACE have been described as belonging to the medial division (MGM) of the medial geniculate body (MGB), a subre- 
gion of the acoustic thalamus. However, recent findings indicate that the projection to ACE originates not in the MGM but in the medial division of the posterior thalamic nucleus (POM), which is displaced medially with respect to the MGB (Farb et al., 1988; LeDoux et al., 1990). Since the POM is not within the projection field of the inferior colliculus (LeDoux et al., 1987; Farb et al., 1988), and thus cannot be considered part of the acoustic thalamus, it appears unlikely that cells in this structure constitute the origin of the thalamo-amygdala projection that underlies the conditioning of fear responses to acoustic stimuli. As a result, it is also unlikely that a direct projection from the thalamus to ACE mediates fear conditioning.

ACE receives an intra-amygdaloid projection from AL (Krettek and Price, 1978b; Roberts et al., 1982; Amaral, 1987; Niteka and Frotscher, 1989). AL, in turn, is the recipient of afferents from the MGM, the suprageniculate nucleus (SG), and the posterior intralaminar nucleus (PIN) (Farb et al., 1988; LeDoux et al., 1990). Since these latter thalamic structures are within the projection field of the inferior colliculus (LeDoux et al., 1985, 1987, 1990; Farb et al., 1988), they could transmit acoustic conditioned stimulus information to $\mathrm{AL}$. AL, therefore, may be the sensory interface of the amygdala in fear conditioning. If so, lesions of $\mathrm{AL}$ should interfere with the conditioning of fear responses to acoustic stimuli.

\section{Materials and Methods}

\section{Animials}

Studies were conducted using male Sprague-Dawley rats weighing 300 $350 \mathrm{gm}$ at the start of the experiment. The animals were individually housed in clear plastic cages and had free access to laboratory chow and water. The housing area was thermally controlled, sealed to sunlight, and maintained on a fluorescent light cycle (on 0600 , off $1800 \mathrm{hr}$ ). All behavioral and surgical procedures were performed during the light phase of the cycle.

\section{Stereotaxic placement of brain lesions}

Rats were anesthetized with Forane (3\% in 100\% oxygen) and placed in a stereotaxic frame. The cranium was exposed and a small burr hole made using a dental drill. A monopolar stainless steel electrode (diameter, $200 \mu \mathrm{m}$ ) insulated with epoxy to within $200 \mu \mathrm{m}$ of the tip was lowered through an incision in the dura to the target brain area. The cathode was connected to the open skin wound. Lesions were made by passing anodal constant current ( $500 \mu \mathrm{A}, 10-15 \mathrm{sec}$ ) through the electrode. The electrode was lowered to the lateral amygdala without passing current for operated, unlesioned controls. All lesions were bilateral, with lesion placement guided by coordinates modified from an atlas of the rat brain (Paxinos and Watson, 1986). The anterior-posterior (AP), medial-lateral (ML), and dorsal-ventral (DV) coordinates were computed relative to the interaural line. Areas targeted for lesions included AL (AP 6.0, ML 5.1, DV 1.9), the posterior caudate-putamen dorsal to AL (AP 6.0, ML 5.1, DV 3.5), and the cortical regions just lateral to AL (AP 6.0, ML 6.3, DV 1.9).

Following completion of surgery, the wound was closed, the anesthesia discontinued, and the animal was placed in its home cage, which rested under a heat lamp. After complete recovery from the anesthesia, the cage was returned to the animal housing area. Body weight, food and water intake, and general health were monitored routinely.

\section{Chronic catheterization for recording arterial pressure}

After at least $12 \mathrm{~d}$ recovery from brain surgery, a catheter was implanted for recording arterial pressure in some animals. Procedures for implantation and maintenance of catheters are described in detail in other publications (Snyder et al., 1978; LeDoux et al., 1984). In brief, a plastic (Tygon) cannula (0.015 inch i.d.) filled with normal saline containing heparin $(100 \mathrm{u} / \mathrm{ml})$ was inserted into the thoracic aorta via the left common carotid artery, and its tip was placed at the level of the diaphragm. With the cannula fixed to the soft tissues with sutures, the free end was passed subcutaneously behind the head to the back of the neck, brought through a stab wound in the neck, and sealed with a stainless steel plug. The neck wound was sutured, and the rat was returned to its home cage and placed in the housing area. The cannula was flushed daily with $0.5 \mathrm{ml}$ of heparinized saline.

\section{Behavioral methods}

Classical conditioning. All rats were conditioned about 2 weeks following brain surgery. The rats were removed from their home cages, placed individually in a rodent conditioning chamber (Coulbourn Instruments, E10-10) enclosed by a sound-attenuating cubicle (Coulbourn Instruments, E10-20), and subjected to classical conditioning trials. The conditioned stimulus (CS) was a sine wave of $800 \mathrm{~Hz}$ produced by a frequency generator (Coulbourn Instruments, S81-06), amplified to $80 \mathrm{~dB}$ (Archer Mini Amplifier), and presented for $10 \mathrm{sec}$ through a speaker mounted on the front panel of the chamber. The unconditioned stimulus (US) consisted of a brief ( $500 \mathrm{msec})$ distributed delivery, through the grid floor, of regulated direct current $(2.2 \mathrm{~mA})$ produced by a grid floor shocker (Coulbourn Instruments, E13-08).

Stimulus presentation was controlled by a microprocessor (IBM-XT) equipped with a digital output board (Opto 22). For the first 10 trials the CS was presented alone and for the next 30 trials the final $500 \mathrm{msec}$ of the CS was coextensive with the US. The intertrial interval was 150 $\mathrm{sec}$ on the average (range, $100-200 \mathrm{sec}$ ). Following the training session, which lasted $103 \mathrm{~min}$, the animal was returned to its home cage and transferred to the housing area.

Pseudoconditioning was controlled for using a random training procedure (Rescorla, 1967). The intensity and duration of the CS and US were the same as above, and the CS was presented on the same schedule as above. However, the onset of the US was randomized with respect to the onset of the CS.

Assessment of conditioned responses. Conditioned responses were tested during extinction trials (no US) conducted in the animal's home cage on the day after conditioning. This procedure allows measurement of responses conditioned to the $\mathrm{CS}$, independent of contextual cues associated with the conditioning environment. The effects of conditioning were examined differently in 2 separate experiments.

In experiment 1 , changes in autonomic reactivity and emotional behavior in the presence of the CS were measured. The autonomic conditioned response that was measured consisted of a stimulus-locked increase in arterial pressure (LeDoux et al., 1984; Iwata and LeDoux, 1988). The behavioral change was the crouching or "freezing" response induced by the presence of the CS (Blanchard and Blanchard, 1972; Bouton and Bolles, 1980; LeDoux et al., 1984). Both the arterial pressure and freezing responses differ in animals given paired versus random presentations of the CS and US and thus reflect associative processes (Iwata et al., 1986a; LeDoux et al., 1986b; Iwata and LeDoux, 1988).

At the time of the cardiovascular test, the home cage was placed inside a sound-attenuating test box and the arterial cannula was connected to a strain-gauge transducer (Statham P23Db), which rested outside the box at the level of the animal's heart. Pulsatile and mean arterial pressure (MAP) werc continuously recorded from the transducer through interlocked input couplers (Beckman 9872; 9806) of a chart recorder (Beckman Dynagraph Type R611). All data were simultaneously recorded on-line by a microcomputer (DEC LSI 11/23), which sampled MAP at $100 \mathrm{~Hz}$. Incoming data were digitized, processed, and stored on disk for subsequent analysis and display.

After the cannula was connected, about $10 \mathrm{~min}$ were allowed for the animal to acclimate to the test box. The CS was then presented to the resting animal 3 times through a speaker located directly above the cage. Stimulus presentation was controlled by the LSI $11 / 23$. The stimulus parameters and delivery schedule were the same as during conditioning. However, if the animal moved during the prestimulus baseline, the trial was aborted and immediately rescheduled. Arterial pressure was recorded by the computer continuously throughout the CS and for the 10 scc preceding and following the CS. After completion of the 3 trials, the home cage was returned to the housing area.

Approximately $2 \mathrm{hr}$ after the cardiovascular test, freezing in the presence of the CS was measured. The home cage was brought into the test room. A new home cage with clean bedding was put into the test box and the rat was placed in it. This procedure elicits a high level of exploratory activity (Bouton and Bolles, 1980; LeDoux et al., 1984). After about $15 \mathrm{sec}$ of continuous activity, the CS was presented for 120 sec. The amount of time accounted for by freezing during the CS was measured with a stopwatch.

In experiment 2 the animals were treated exactly as in experiment 1 
a CAUDAL

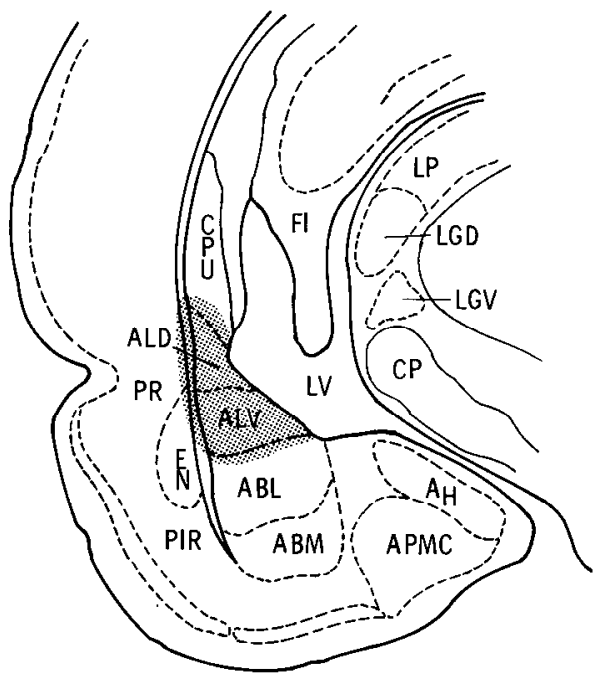

b INTERMEDIATE

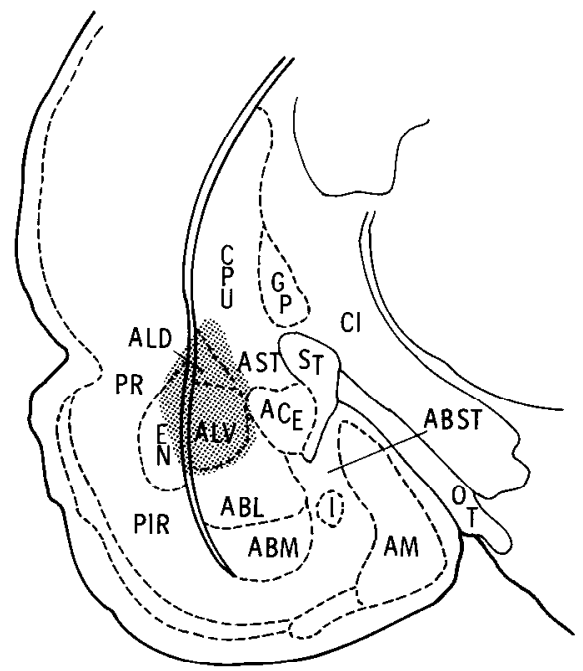

C ROSTRAL

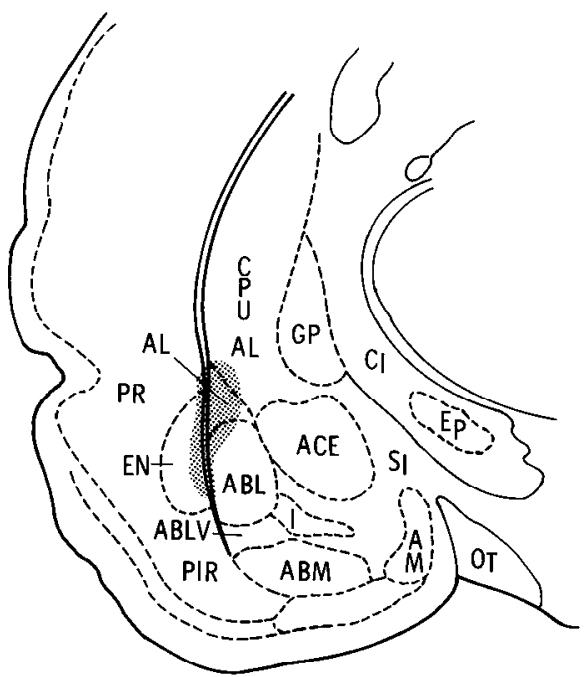

Figure 1. Typical bilateral lesions of the lateral nucleus of the amygdala are illustrated on drawings of frontal sections through the caudal (a), intermediate $(b)$, and rostral $(c)$ thirds of the amygdala. The lesions completely destroy the lateral amygdala at the level where the stria terminalis forms the medial border of the central amygdaloid nucleus (level b). Lesions that did not meet this criterion were eliminated from the experimental group.

up until the time of conditioned response assessment, except that they were deprived of water 12-15 hr prior to conditioning. Freezing in the presence of the CS was then measured about $20 \mathrm{hr}$ following conditioning, as described above. About $2 \mathrm{hr}$ later, the suppression of licking behavior by the CS was measured. At the time of the lick-suppression test, the rat's home cage was transferred to the observation chamber. After 10 min, a drinking tube filled with $10 \%$ sucrose was made available. After $10 \mathrm{sec}$ of continuous licking, the CS was presented. The effects of fear conditioning were assessed by calculating the amount of time spent licking during $120 \mathrm{sec}$ of the CS.

\section{Histology}

Following completion of the behavioral studies, the animals were given an overdose of sodium pentobarbital $(120 \mathrm{mg} / \mathrm{kg})$ and perfused with normal saline and $10 \%$ buffered formalin. The brains were stored in buffered formalin and were later frozen and sectioned on a microtome at $40 \mu \mathrm{m}$. Every fourth section was collected in phosphate buffer $(\mathrm{pH}$ 7.4), mounted on gelatin-coated slides, and stained with thionin. Lesion location was plotted using an overhead projector.

\section{Results}

\section{Experiment 1}

\section{Histological observations}

Bilateral lesions aimed at the lateral amygdala were made in 29 rats. Animals were included in the experimental group on the basis of histological criteria. Specifically, if AL was completely destroyed bilaterally in the anterior-posterior center of the nucleus (the level at which the stria terminalis encapsulates the medial border of ACE), the animal was included, provided that the lesion did not also invade the adjacent central nuclcus of the amygdala. Using these guidelines, 6 of the 29 animals were ultimately included in the lateral amygdala group. Typical lesions are illustrated in Figures 1 and 2.

The low rate of success in accurately placing lesions in $\mathrm{AL}$ is due to its small size and its proximity to ACE. Ten animals with bilateral but incomplete damage to the target portion of $\mathrm{AL}$ were placed in a lesioned control group (Partial Lesions). In these cases, either the medial, dorsal, or ventral aspect of AL was partially spared at the target level on at least one side of the brain. Three animals had bilateral lesions that completely missed AL and are included as a second lesioned control group (Missed Lesions). Eight animals were excluded from the data analysis because the lesions failed to meet any of the criteria described above (either the lesion was too large and/or damaged the ACE or AL was only damaged unilaterally).

For 2 additional control groups, lesions were intentionally placed in either the caudate putamen just dorsal to $\mathrm{AL}(n=7)$ or in the cortex immediately adjacent to $\operatorname{AL}(n=4)$. Lesions from these latter 2 groups are illustrated in Figure 2.

Lesions were also placed in AL in a group of 11 animals given random training. Since we expected that these lesions would not affect responses elicited by the CS after random training, the strict criteria used above were relaxed. The lesions were intentionally made slightly larger (by increasing the duration of current delivery from 10 to $15 \mathrm{sec}$ ), and lesions that spread to adjacent areas, such as the central nucleus of the amygdala, were accepted, as long as the lateral amygdala was completely damaged at the level where the stria terminalis extends along the medial border of the ACE. Using these criteria, 6 of the 11 animals had acceptable lesions.

Figure 2. Photomicrographs of representative lesions of the lateral nucleus of the amygdala (c), caudate putamen just dorsal to the lateral nucleus of the amygdala $(b)$, and cortex just lateral to the lateral nucleus of the amygdala $(d)$. Cytoarchitecture of the lesioned areas is illustrated in the drawing in $a$. 

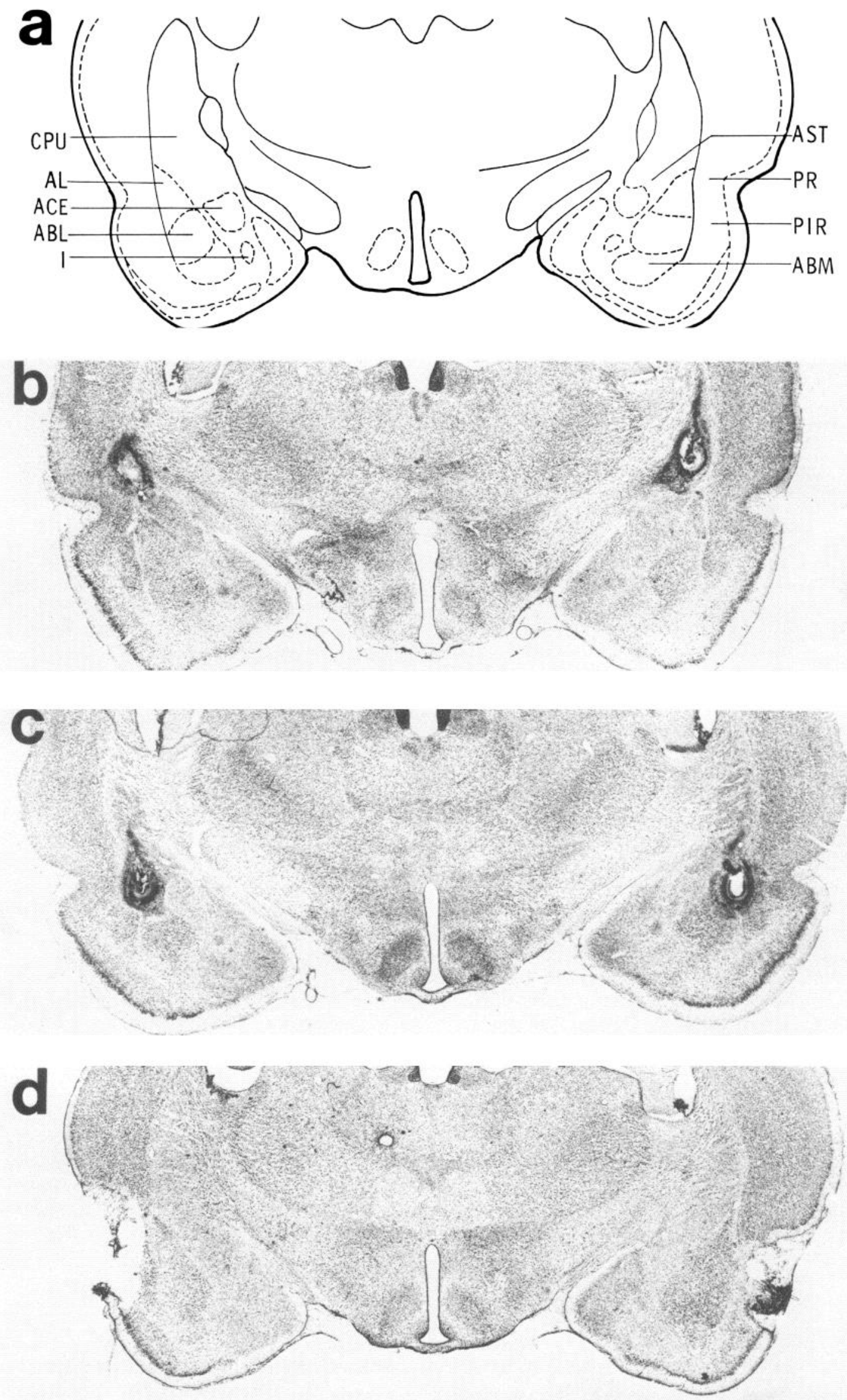
LATERAL AMYGDALA LESIONS
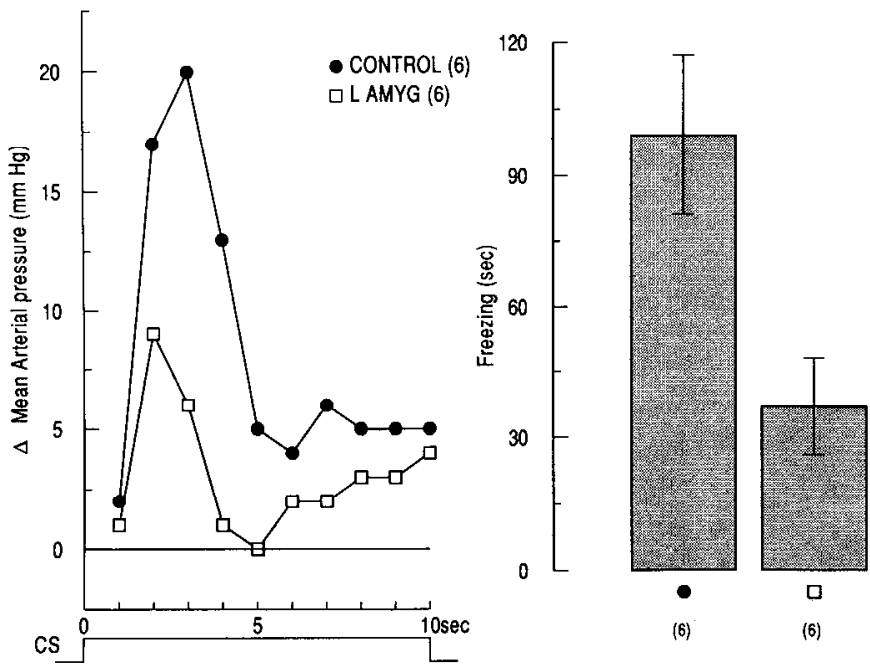

Figure 3. Bilateral destruction of the lateral amygdaloid nucleus significantly reduced the elevation of arterial pressure and the duration of "freezing" evoked by the conditioned stimulus.

\section{Effects of lateral amygdala lesions on conditioned emotional responses}

In the sham-lesioned control group $(n=6)$, the CS evoked stereotyped increascs in mean arterial pressurc and freczing bchavior (Fig. 3), as we have typically observed (LeDoux et al., 1984, 1986b, 1988; Iwata et al., 1986a). In the animals with acceptable bilateral lesions of $\mathrm{AL}(n=6)$, the pressor and freezing responses were both greatly reduced (Fig. 3). In contrast, the arterial pressure and freezing responses in animals with incomplete lesions of the lateral amygdala $(n=10)$ and in animals with lesions which were accidentally placed ventral to $\mathrm{AL}(n=$ 3) were similar to responses of the sham-lesioned control group (Fig. 4). Responses in animals with lesions intentionally placed in the caudate-putamen dorsal to $\mathrm{AL}(n=7)$ and in the cortex lateral to $\mathrm{AL}(n=4)$ were also similar to those in the shamoperated group (Fig. 5).

A 2-way analysis of variance with one-repeated measure was performed on the arterial pressure data from these 5 groups. The factors were Group (sham-lesioned control, lesion of AL, partial lesion of $\mathrm{AL}$, missed lesion of $\mathrm{AL}$, lesion of caudate putamen dorsal to $A L$, and lesion of cortex lateral to $A L$ ) and Time (seconds 1-10 during the CS). The main effect of Group was not significant $[F(5,34)=2.23, p=0.074]$, but the repeated measure, Time $[F(9,306)=52.47, p<0.001]$, and the interaction between Group and Time $[F(45,306)=2.34, p<0.001]$ were. Post hoc comparison with the Tukey test determined that the AL lesioned group, but none of the others, differed from the sham-lesioned control group $(p<0.01)$. A 1-way analysis of variance performed on the freezing data resulted in a significant effect $[F(5,34)=3.12, p<0.01]$. Post hoc comparison with the Tukey test showed that the AL group, but none of the other groups, differed in freezing time relative to the control group ( $p$ $<0.05$ ).

Lesions of AL thus reduce but do not completely eliminate the arterial pressure and freezing responses evoked by the CS (see Fig. 3). As illustrated in Figure 6, the remaining responses are similar to the responses evoked by the CS following random
INACCURATE LESIONS
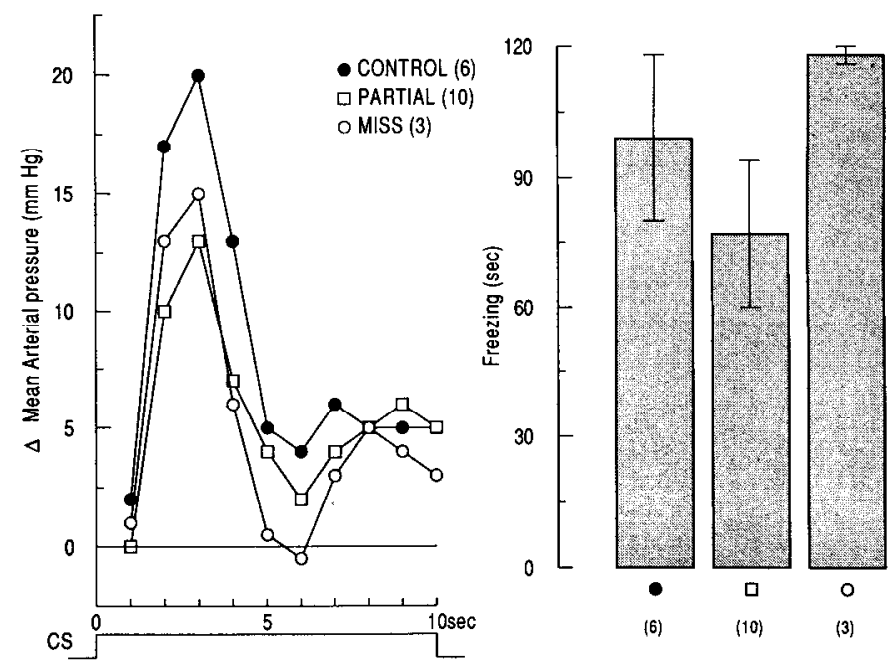

Figure 4. Bilateral lesions that only partially destroyed the lateral amygdala or that missed the lateral amygdala did not significantly reduce the arterial pressure or freezing responses. Compare these findings with the effects of complete lesions of lateral amygdala, as shown in Figure 3 .

presentations of the CS and US in sham-lesioned controls ( $n=$ 8). Moreover, lesions of AL $(n=6)$ do not eliminate the smallmagnitude response evoked by the CS following random training (Fig. 6). A 2-way analysis of variance of the arterial pressure data produced an insignificant $F$ statistic for the effect of group $[F(2,17)=1.36, \mathrm{~ns}]$ and for the interaction between Group and the repeated measure Time $[F(9,153)=0.76, \mathrm{~ns}]$. A 1-way analysis of variance of the freezing data also produced an insignificant result $[F(2,17)=1.13 ; \mathrm{ns}]$.

In summary, lesions of $\mathrm{AL}$ reduce, but do not eliminate, the responses evoked by the CS in conditioned animals. However, the responses remaining are comparable to those in animals given nonassociative training. Moreover, AL lesions fail to interfere with the expression of the small-magnitude responses evoked following nonassociative training.

\section{Experiment 2}

Because of the strict histological criteria used, a large proportion of the total number of animals lesioned were excluded from the primary experimental group in the first experiment. It is possible, though unlikely, that this selection procedure biased the results. We therefore made lesions of AL in an additional group of 66 animals and examined the effects of these lesions on emotional conditioning. Since there was no evidence for a differential effect on autonomic and behavioral conditioned responses in the first experiment, and since it is much easier to conduct the studies if the animals do not have to be cannulated, we only measured behavioral responses in this experiment. However, we used two different behavioral tests: freezing and lick suppression.

\section{Histological observations}

Lesions were evaluated using the criteria described in experiment 1 . As before, adherence to strict analytic criteria resulted in a low rate of success. Acceptable bilateral lesions of AL were found in 8 rats. The lesions were comparable to those illustrated 

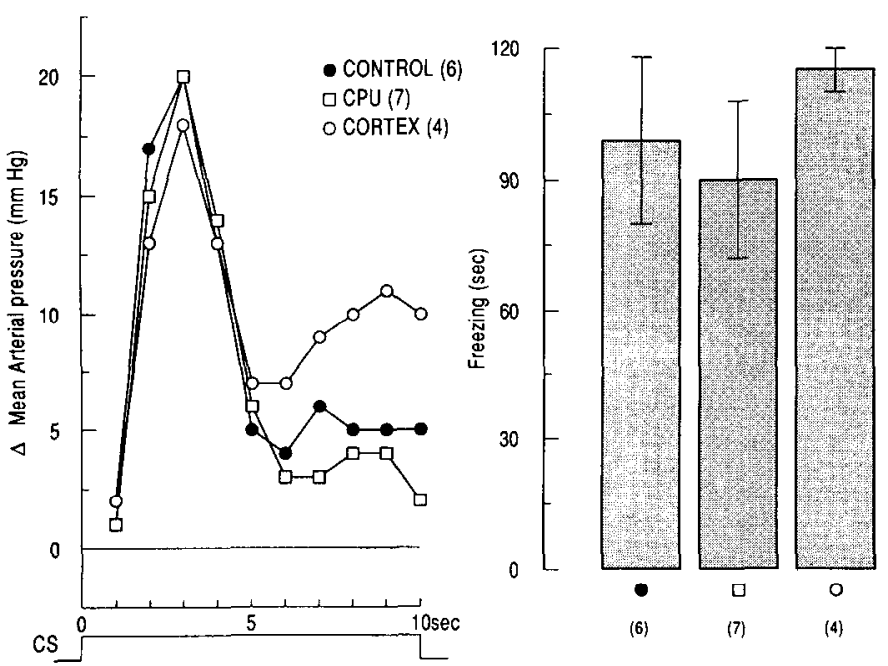

Figure 5, Lesions of the caudate-putamen just dorsal to the lateral nucleus of the amygdala or of the cortex just lateral to the lateral nucleus of the amygdala did not significantly affect the arterial pressure or freezing responses.

in Figures 1 and 2 . In the remaining rats, the lesions either missed AL or were too large or incomplete.

\section{Effects of lesions of the lateral amygdala on conditioned emotional responses}

Rats in the sham-lesioned group ( $n=24$ ) exhibited freezing during most of the CS. As shown in Figure 7, significantly less freezing was seen in the rats $(n=8)$ with acceptable lesions of $\operatorname{AL}[F(1,30)=33.37, p<0.001]$. The magnitude of the effect of AL lesions on freezing was essentially the same as in experiment 1.

The CS suppressed licking behavior in the control group (Fig. 7). Rats with lesions of AL drank significantly more than rats in the control group during the $\mathrm{CS}[F(1,30)=32.435, p<$ $0.001]$. AL lesions interfere with the conditioned suppression of licking by the CS, as well as with conditioned freezing.

\section{Discussion}

In the present study we have demonstrated that electrolytic lesions of $\mathrm{AL}$ interfere with the aversive classical conditioning of behavioral and autonomic emotional responses to acoustic stimuli. Animals with lesions of AL perform similar to unlesioned animals given nonassociative (random) presentations of the CS and US. AL, therefore, may be an essential link in the neural pathway underlying the association of the CS with the US in aversive classical conditioning.

One of the efferent connections of the lateral amygdala is ACE (Krettek and Price, 1978b; Roberts et al., 1982; Amaral, 1987). As described in the introductionary remarks, ACE is believed to be a critical site of emotional integration and appears to be the origin of pathways by which specific response systems are controlled by emotional information. If, as we suggested, ACE is dependent upon $\mathrm{AL}$ in its control of emotional responses evoked by sensory stimuli, lesions of AL should have the effects we observed.

The AL is adjacent to ACE. However, it is unlikely that in-

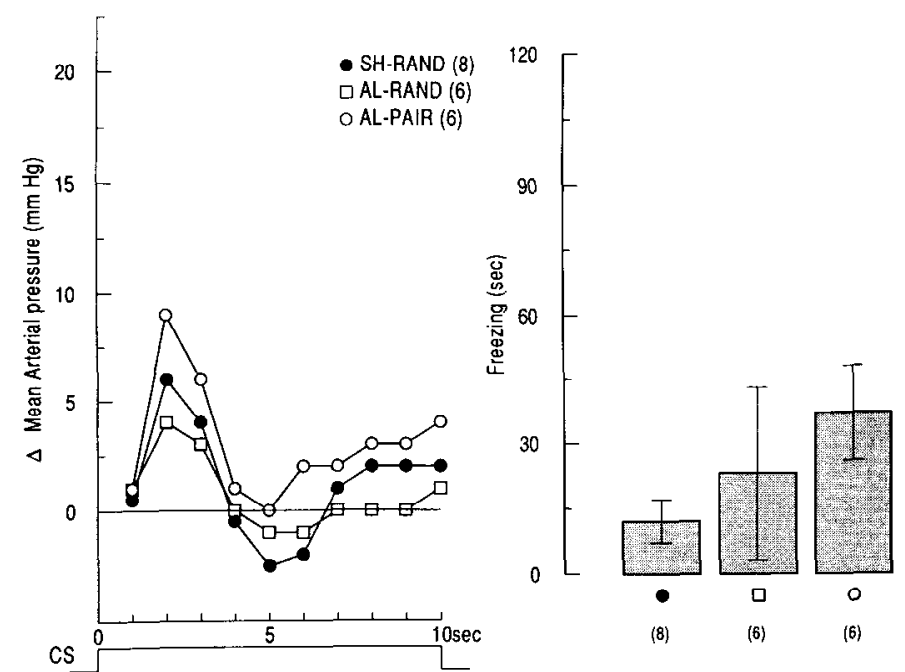

Figure 6. The arterial pressure and freezing responses evoked by the $\mathrm{CS}$ in animals with lateral amygdala lesions $(A L-P A I R)$ are not different from those in sham operated animals given nonassociative (random) presentations of the CS and US (SH-RAND). The performance of animals given random traning after lateral amygdala lesions $(A L-R A N D)$ is similar to that of animals given random traning after sham operation. Thus, following lateral amygdala lesions rats perform as if they have been given random rather than paired presentations of the CS and US.

cidental damage to ACE accounts for the effects of AL on conditioned responses. Animals with damage that spread to $A C E$ were eliminated from this part of the study. Also, since fibers originating in the thalamus and terminating in and near ACE enter the amygdala medially (LeDoux et al., 1985), it is unlikely

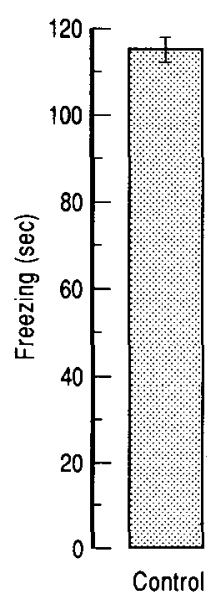

(24)

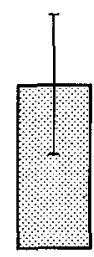

AL

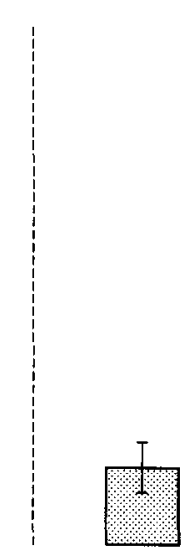

Control

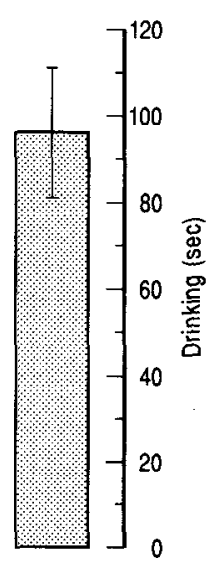

$\mathrm{AL}$

Figure 7. In a second experiment, the effects of lateral amygdala lesions were reexamined. Two separate behavioral measures of fear conditioning were used. As in the first experiment (see Fig. 3), lesions of the lateral amygdala greatly reduced the duration of "freezing" in the presence of the CS (left). Also, the CS suppressed drinking behavior less in animals with lateral amygdala lesions, as indicated by the greater amount of time the lesioned animals spent drinking during the CS (right). Less freezing and more drinking during the CS both indicate that lateral amygdala lesions interfere with fear conditioning. 
that AL lesions disrupted thalamic projections to the central amygdala and thereby interfered with fear conditioning.

Nevertheless, we cannot be certain whether the effects of AL lesions are due to damage to local neurons or to fibers passing through the region. Our working hypothesis, though, is that AL is the sensory interface of the amygdala and that lesions of this region interfere with aversive conditioning by blocking the synaptic transmission of the acoustic CS to the amygdala.

Our view that $\mathrm{AL}$ is the sensory interface of the amygdala is supported by the fact that the main afferents to this structure originate in sensory processing areas of the thalamus and cortex (Whitlock and Nauta, 1956; Herzog and van Hoesen, 1975; Aggleton et al., 1980; Turner et al., 1980; Russchen, 1982; LeDoux et al., 1984, 1985, 1987, 1990; Amaral, 1987). Unit recording studies have shown that ncurons in $\mathrm{AL}$ respond to acoustic, visual, and somatic stimuli (Le Gal La Salle and BenAri, 1981). Moreover, electrical stimulation of the acoustic thalamus, the region believed to be afferent to the lateral amygdala in the conditioning circuit, elicits short-latency excitatory action potentials in AL (LeDoux et al., 1986a; Clugnet et al., 1990).

AL contains a high concentration of benzodiazepine receptors (Young and Kuhar, 1980; Niehoff and Kuhar, 1983) and injection of benzodiazepines directly into $\mathrm{AL}$ attenuates fear responses (Scheel-Kruger and Petersen, 1982). These observations, in light of the fact that the main afferents to $A L$ arise in sensory processing areas (see above), suggest that benzodiazepines may, in part, relieve fear and anxiety by gating sensory inputs to the amygdala or otherwise reducing the propensity of sensory stimuli to activate the emotional circuits organized through the amygdala.

AL may also be a site of neural plasticity during emotional learning. Studies of cats have shown that the firing pattern of AL neurons to auditory or visual stimuli can be modified by pairing these stimuli with somatic stimulation (Le Gal La Salle and Ben-Ari, 1981). Moreover, AL contains a high concentration of excitatory amino acid receptors, including NMDA receptors (Monaghan and Cotman, 1985), which have been shown to play an important role in long-term synaptic potentiation (LTP) in the hippocampus (see Cotman and Monaghan, 1988). LTP has been produced in vitro in AL brain slices (Chapman and Brown, 1988) and in vivo in AL by stimulation of the acoustic thalamus (Clugnet and LeDoux, 1989). Moreover, glutamate, one of the major excitatory transmitters in the brain and a major ligand for NMDA receptors, is present in the cells of origin of the thalamo-amygdala projection and in presynaptic terminals in $\mathrm{AL}$ (Farb et al., 1989), and blockade of excitatory amino acid receptors interferes with the excitation of AL neurons by MGB stimulation (Clugnet and LeDoux, 1989).

In conclusion, $\mathrm{AL}$ is an essential link in the circuitry underlying auditory fear conditioning. It appears to be the sensory gateway to the amygdala and may also be a site of emotional modulation and cellular plasticity.

\section{Appendix}

\section{Abbreviations}

ABL, amygdala, basolateral nucleus;

ABLV, amygdala, lateral ventral basolateral nucleus;

ABM, amygdala, basomedial nucleus:

ABST, amygdaloid portion of the BNST;

$\mathrm{ACE}, \quad$ amygdala, central nucleus;

AH, amygdalo-hippocampal area;

AL, amygdala, lateral nucleus;
ALD, amygdala, dorsal lateral nucleus;

ALV, amygdala, ventral lateral nucleus;

AM, amygdala, medial nucleus;

AST, amygdalostriatal transition zone;

BNST, bed nucleus of the stria terminalis:

CI, internal capsule;

CPU, caudate putamen;

EN, endopiriform nucleus;

EP, entopeduncular nucleus;

FI, fimbria;

GP, globus pallidus;

I, intercalated nucleus of the amygdala;

L-AMYG, amygdala, lateral nucleus;

LGD, lateral geniculate body, dorsal part;

LGV, lateral geniculate body, ventral part;

LV, lateral ventricle;

OT, $\quad$ optic tract;

PIR, piriform cortex;

PR, perirhinal cortex;

SI, substantia innominata; and

ST, stria terminalis

\section{References}

Aggleton, J. P., M. J. Burton, and R. E. Passingham (1980) Cortical and subcortical afferents to the amygdala of the rhesus monkey ( $\mathrm{Ma}$ caca mulatta). Brain Res. 190: 347-368.

Amaral, D. (1987) Memory: Anatomical organization of candidate brain regions. In Handbook of Physiology. Sect. 1: Neurophysiology, Vol. 5: Higher Functions of the Brain, F. Plum, ed., pp. 211-294, American Physiological Society, Bethesda, MD.

Applegate, C. D., R. C. Frysinger, B. S. Kapp, and M. Gallagher (1982) Multiple unit activity recorded from amygdala central nucleus during Pavlovian heart rate conditioning in rabbit. Brain Res. 238: 457-462.

Blanchard, D. C., and R. J. Blanchard (1972) Innate and conditioned reactions to threat in rats with amygdaloid lesions. J. Comp. Physiol. Psychol. 81: 281-290.

Bouton, M. E., and R. C. Bolles (1980) Conditioned fear assessed by freezing and by the suppression of three different baselines. Anim. Learn. Behav. 8: 429-434.

Chapman, P. F., and T. H. Brown (1988) Long-term potentiation in amygdala brain slices. Soc. Neurosci. Abstr. 14: 566.

Clugnet, M. C., and J. E. LeDoux (1989) Long term potentiation (LTP) in the lateral amygdala (AL) in response to stimulation of the medial geniculate body (MGB). Soc. Neurosci. Abstr. 15: 891 .

Clugnet, M. C., J. E. LeDoux, and S. F. Morrison (1990) Unit responses evoked in the amygdala and striatum by electrical stimulation of the medial geniculate body. J. Neurosci. 10: 1055-1061.

Cotman, C. W., D. T. Monaghan, and A. H. Ganong (1988) Excitatory amino acid neurotransmission: NMDA receptors and Hebb-type synaptic plasticity. Annu. Rev. Neurosci. 11: 61-80.

Farb, C. F., D. A. Ruggiero, and J. E. LeDoux (1988) Projections from the acoustic thalamus terminate in the lateral but not central amygdala. Soc. Neurosci. Abstr. 14: 1227.

Farb, C. F., J. E. LeDoux, and T. A. Milner (1989) Glutamate is present in medial geniculate body neurons that project to lateral amygdala and in lateral amygdala presynaptic terminals. Soc. Neurosci. Abstr. 15: 890 .

Francis, J., L. L. Hernandez, and D. A. Powell (1981) Lateral hypothalamic lesions: Fffects on Pavlovian cardiac and eyeblink conditioning in the rabbit. Brain Res. Bull. 6: 155-163.

Galeno, T., and M. J. Brody (1983) Hemodynamic responses to amygdaloid stimulation in spontaneously hypertensive rats. Am. J. Physiol. 245: R281-R286.

Gallagher, M., B. S. Kapp, J. P. Pascoe, and R. P. Rapp (1981) A neuropharmacology of the amygdala systems which contribute to learning and memory. In The Amygdaloid Complex, Y. Ben-Ari, ed., pp. 343-354, Elsevier, Amsterdam.

Gentile, C. G., T. W. Jarrel, A. Teich, P. M. McCabe, and N. Schneiderman (1986) The role of amygdaloid central nucleus in the retention of differential Pavlovian conditioning of bradycardia in rabbits. Behav. Brain Res. 20: 263-273.

Herzog, A. G., and G. W. van Hoesen (1975) Temporal neocortical afferent connections to the amygdala in the rhesus monkey. Brain Res. 115: 57-69. 
Hitchcock, J. M., and M. Davis (1986) Amygdala lesions block fearenhanced startle using either visual or auditory conditioned stimuli. Soc. Neurosci Abstr. 12: 752.

Hopkins, D. A., and G. Holstedge (1978) Amygdala projections to the mesencephalon, pons and medulla oblongata in the cat. Exp. Brain Res. 32: 529-547.

Iwata, J., and J. E. LeDoux (1988) Dissociation of associative and nonassociative concommitants of classical fear conditioning in the freely behaving rat. Behav. Neurosci. 102: 66-76.

Iwata, J., J. E. LeDoux, M. P. Meeley, S. Arneric, and D. J. Reis (1986a) Intrinsic neurons in the amygdaloid field projected to by the medial geniculate body mediate emotional responses conditioned to acoustic stimuli. Brain Res. 383: 195-214.

Iwata, J., J. E. LeDoux, and D. J. Reis (1986b) Destruction of intrinsic neurons in the lateral hypothalamus disrupts cardiovascular but not behavioral conditioned emotional responses. Brain Res. 368: 161166.

Iwata, J., K. Chida, and J. E. LeDoux (1987) Cardiovascular responses elicited by stimulation of neurons in the central amygdaloid nucleus in awake but not anesthetized rats resemble conditioned emotional responses. Brain Res. 418: 183-188

Jones, E. G., and T. P. S. Powell (1970) An experimental study of converging sensory pathways within the cerebral cortex of the monkey. Brain 93: 793-820.

Kapp, B. S., R. C. Frysinger, M. Gallagher, and J. R. Haselton (1979) Amygdala central nucleus lesions: Effects on heart rate conditioning in the rabbit. Physiol. Behav. 23: 1109-1117.

Kapp, B. S., M. Gallagher, M. D. Underwood, C. L. McNall, and D. Whitehorn (1982) Cardiovascular responses elicited by stimulation of the amygdala central nucleus in the rabbit. Brain Res. 234: $251-$ 262

Krettek, J. E., and J. L. Price (1978a) Amygdaloid projections to subcortical structures within the basal forebrain and brainstem in the rat and cat. J. Comp. Neurol. 178: 225-253.

Krettek, J. E., and J. L. Price (1978b) A description of the amygdaloid complex in the rat and cat with observations on intra-amygdaloid connections. J. Comp. Neurol. 178: 255-280.

LeDoux, J. E., A. Sakaguchi, and D. J. Reis (1984) Subcortical efferent projections of the medial geniculate nucleus mediate emotional responses conditioned by acoustic stimuli. J. Neurosci. 4: 683-698.

LeDoux, J. E., D. A. Ruggiero, and D. J. Reis (1985) Projections to the subcortical forebrain from anatomically defined regions of the medial geniculate body in the rat. J. Comp. Neurol. 242: 182-213.

LeDoux, J. E., S. F. Morrison, and D. J. Reis (1986a) The geniculoamygdala projection: Electrophysiological characteristics of cells in a fear conditioning pathway. Soc. Neurosci. Abstr. 12: 748.

LeDoux, J. E., A. Sakaguchi, J. Iwata, and D. J. Reis (1986b) Interruption of projections from the medial geniculate body to an archineostriatal field disrupts the classical conditioning of emotional responses to acoustic stimuli. Neuroscience 17:615-627.

LeDoux, J. E., D. A. Ruggiero, R. Forrest, R. Stornetta, and D. J. Reis (1987) Topographic organization of convergent projections to the thalamus from the inferior colliculus and spinal cord in the rat. J. Comp. Neurol. 264: 123-146.

LeDoux, J. E., J. Iwata, P. Cicchett, and D. J. Reis (1988) Different projections of the central amygdaloid nucleus mediate autonomic and behavioral correlates of conditioned fear. J. Neurosci. 8: 2517-2529.

LeDoux, J. E., C. Farb, and D. A. Kuggiero (1990) Topographic organization of neurons in the acoustic thalamus that project to the amygdala. J. Neurosci. 10: 1043-1054.

Le Gal La Salle, G., and Y. Ben-Ari (1981) Unit activity in the amygdaloid complex: A review. In The Amygdaloid Complex, Y. Ben-Ari, ed., pp. 227-237, Elsevier, Amsterdam.
Monaghan, D. T., and C. W. Cotman (1985) Distribution of n-methylD-aspartate sensitive $\mathrm{L}-(3 \mathrm{H})$ glutamate-binding sites in rat brain. $\mathrm{J}$. Neurosci. 5: 2909-2919.

Niehoff, D. L., and M. J. Kuhar (1983) Benzodiazepine receptors: Localization in rat amygdala. J. Neurosci. 10: 2091-2097.

Niteka, L., and M. Frotscher (1989) Organization and synaptic interconnections of GABAergic and cholinergic elements in the rat amygdaloid nuclei: single- and double-immunolabeling studies. J. Comp. Neurol. 279; 470-488.

Ottersen, O. P., and Y. Ben-Ari (1979) Afferent conncetions to the amygdaloid complex of the rat and cat: Projections from the thalamus. J. Comp. Neurol. 187: 401-424.

Pascoe, J. P., and B. S. Kapp (1985) Electrophysiological characteristics of amygdaloid central nucleus neurons during Pavlovian fear conditioning in the rabbit. Behav. Brain Res. 16: 117-133.

Paxinos, G. and C. Watson (1986) The Rat Brain in Stereotaxic Coordinates, Academic, Sydney.

Price, J. L., and D. G. Amaral (1981) An autoradiographic study of the projections of the central nucleus of the monkey amygdala. $J$. Neurosci. $1:$ 1242-1259.

Reis, D. J., and M. C. Oliphant (1964) Bradycardia and tachycardia following electrical stimulation of the amygdaloid region in the monkey. J. Neurophysiol. 27: 893-912.

Rescorla, R. A. (1967) Pavlovian conditioning and its proper control procedures. Psychol. Rev. 74: 71-80.

Roberts, G. W., P. L. Woodhams, J. M. Polak, and T. J. Crow (1982) Distribution of neuropeptides in the limbic system of the rat: The amygdaloid complex. Neuroscience 7: 99-131.

Russchen, F. T. (1982) Amygdalopetal projections in the cat. II. Subcortical afferent connections. A study with retrograde tracing techniques. J. Comp. Neurol. 207: 157-176.

Scheel-Kruger, J., and E. N. Petersen (1982) Anticonflict effect of the benzodiazepines mediated by a GABAergic mechanism in the amygdala. Eur. J. Pharmacol. 82: 115-116.

Schwaber, J. S., B. S. Kapp, G. A. Higgins, and P. R. Rapp (1982) Amygdaloid and basal forebrain direct connections with the nucleus of the solitary tract and the dorsal motor nucleus. J. Neurosci. 2: $1424-1438$

Smith, O. A., C. A. Astley, J. L. DeVito, J. M. Stein, and R. E. Walsh (1980) Functional analysis of hypothalamic control of the cardiovascular responses accompanying emolional behavior. Fed. Proc. 29: 2487-2494.

Snyder, D. W., M. A. Nathan, and D. J. Reis (1978) Chronic lability of arterial pressure produced by selective destruction of the catecholamine innervation of the nucleus tractus solitarii in rat. Circ. Res. 43: $662-671$.

Turner, B., and N. Herkenham (1981) An autoradiographic study of thalamo-amygdaloid connections in the rat. Anat. Rec. 199: 260A.

Turner, B. H., M. Mishkin, and M. Knapp (1980) Organization of the amygdalopetal projections from modality-specific cortical association areas in the monkey. J. Comp. Neurol. 191: 515-543.

Van der Kooy, D., L. Y. Koda, J. F. McGinty, C. R. Gerfen, and F. E. Bloom (1984) The organization of projections from the cortex, amygdala and hypothalamus to the nucleus of the solitary tract in rat. J. Comp. Neurol. 224: 1-24.

Veening, J. G. (1978) Subcortical afferents of the amygdaloid complex in the rat: An HRP study. Neurosci. Lett. 8: 197-202.

Whitlock, D. G., and W. J. H. Nauta (1956) Subcortical projections from the temporal neocortex in Macaca mulatta. J. Comp. Neurol. 106: 183-212.

Young, W. S. III, and M. J. Kuhar (1980) Radiohistochemical localization of benzodiazepine receptors in rat brain. J. Pharmacol. Exp. Ther. 212: 337-346. 